\title{
Avaliação do emprego de microfiltração para remoção de fibras do efluente de branqueamento de polpa celulósica
}

\author{
Evaluation of the use of microfiltration for removal of fiber \\ from bleaching pulp mill effluent
}

\begin{abstract}
Míriam Cristina Santos Amaral
Engenheira Química, Doutora em Saneamento, Meio Ambiente e Recursos Hídricos pelo Departamento de Engenharia Sanitária e Ambiental (DESA) da Universidade Federal de Minas Gerais (UFMG). Professora Adjunta do DESA da UFMG - Belo Horizonte (MG), Brasil.
\end{abstract}

\begin{abstract}
Laura Hamdan de Andrade
Engenheira Química, Mestranda em Saneamento, Meio Ambiente e Recursos Hídricos pelo DESA da UFMG - Belo Horizonte (MG), Brasil.
\end{abstract}

Liséte Celina Lange

Química, Doutora em Tecnologia Ambiental pela University of London - Londres, Reino Unido. Professora Associada do DESA da UFMG - Belo Horizonte (MG), Brasil.

\section{Cristiano Piaseck Borges}

Engenheiro Químico, Doutor em Engenharia Química pela Universidade Federal do Rio de Janeiro (UFRJ). Professor Adjunto do Programa de Engenharia Química da UFRJ - Rio de Janeiro (RJ), Brasil.

\section{Resumo}

O processo de branqueamento é o estágio em que ocorre a maior perda de fibras durante a fabricação de polpa celulósica. Além de ser uma perda de produto, estas fibras aumentam a concentração de matéria orgânica do efluente dificultando seu tratamento. O objetivo deste trabalho foi avaliar o emprego de microfiltração (MF) na remoção de fibras de efluente de branqueamento alcalino de polpa celulósica. Foi empregada membrana de poli(éter imida) com tamanho médio de poros de 0,5 $\mu \mathrm{m}$ e área de filtração de 0,05 $\mathrm{m}^{2}$. O efeito das condições operacionais no fluxo permeado foi avaliado através do monitoramento do perfil de fluxo durante a operação em diferentes condições de velocidade de escoamento (Reynolds de 1.226, 1.653 e 2.043), pH da alimentação $(7,10$ e 10,6), temperatura $(28,43$ e 48 $\mathrm{C})$ e pressão de operação através da avaliação da pressão crítica. Os resultados mostraram que a MF é um processo eficiente para remoção de fibras, apresentado 99\% eficiência de remoção de sólidos suspensos. O melhor desempenho da operação de MF foi obtido empregando pH 7, pressão de 1 bar e Re de 1.653. Os resultados mostram que a redução do fluxo se deve principalmente à formação de torta.

Palavras-chave: microfiltração; efluente do branqueamento alcalino; incrustação.

\begin{abstract}
The bleaching process is the stage where there is the greatest loss of fibers during the pulp production. Besides being a waste of product, these fibers increase the concentration of organic matter in the effluent and make the treatment of effluent more difficult. The aim of this study was to evaluate the use of microfiltration (MF) in the removal of fiber of effluent of alkaline bleaching pulp mill. The membrane employed was hollow fiber poly (ether imide), with average pore size of $0.5 \mu \mathrm{m}$ and filtration area of $0.05 \mathrm{~m}^{2}$. The effect of operating conditions on the permeate flux was evaluated by monitoring the flux profile during operation in different conditions of flow velocity (Reynolds 1,226, 1,653 and 2,043), $\mathrm{pH}$ of feeding (7, 10 and 10.6), temperature $\left(28,43\right.$, and $\left.48^{\circ} \mathrm{C}\right)$ and pressure operation by evaluating the critical pressure. The results showed that MF is an efficient process for removal of fiber, with $99 \%$ removal efficiency of suspended solids. The best performance of the operation of MF was obtained using pH 7, 1 bar and Reynolds number of 1,653 . The results show that the flow reduction is mainly due to cake formation.
\end{abstract}

Keywords: microfiltration; effluent of alkaline bleaching pulp mill; fouling.

Endereço para correspondência: Miriam Cristina Santos Amaral - Universidade Federal de Minas Gerais, Departamento de Engenharia Sanitária e Ambiental - Avenida Antônio Carlos, 6.627 - Pampulha - 31270-901 - Belo Horizonte (MG), Brasil - E-mail: miriam@desa.ufmg.br

Recebido: 16/03/12 - Aceito: 05/04/13 - Reg. ABES: 287 


\section{Introdução}

A planta de branqueamento é responsável pela maior carga de efluente na indústria de polpa celulósica, valores típicos oscilam entre $20-40 \mathrm{~m}^{3}$ de efluente gerados por tonelada de polpa produzida (IPCC, 2001), contribuindo com $85 \%$ da cor total e $50 \%$ da demanda bioquímica de oxigênio (DBO). Entretanto, a elevada DBO e/ou demanda química de oxigênio (DQO) encontrada não é a única dificuldade enfrentada no tratamento deste efluente. O maior problema é a presença de compostos caracterizados pela elevada toxicidade tais como clorofenóis, cloroligninas, ácidos orgânicos, resinas ácidas, dioxinas e seus derivados, somado ainda à presença de fibras (SOARES \& DURÁN, 2001).

O processo de branqueamento é o estágio em que ocorre a maior perda de fibras durante a fabricação de polpa celulósica, cerca de 1\% de fibra é descartada nos efluentes (IPCC, 2001). Além de representar uma perda de produto, estas fibras aumentam significativamente a concentração de matéria orgânica do efluente dificultando seu tratamento. Isto significa que a recuperação de fibras é benéfica tanto para o processo, assim como para o controle da poluição.

Um grande número de empresas emprega o tratamento conjunto dos efluentes gerados em todos os estágios de produção utilizando processos biológicos, principalmente lodos ativados. Estes sistemas conseguem redução média de 90 a 95\% para DBO, mas de apenas 40 a $60 \%$ para a DQO (BRYANT et al., 1992; GRAVES \& JOYCE, 1994). A presença de fibras de celulose é responsável por essas baixas eficiências, pois, além de apresentarem baixa biodegradabilidade, geralmente passando inalteradamente por estes processos, dificultam a transferência de massa de oxigênio dentro dos reatores e a decantação posterior do lodo.

Neste sentido, o que tem sido adotado é a inserção de decantadores primários ou tanques de coagulação/floculação como pré-tratamento dos processos biológicos para a remoção destas fibras (THOMPSON et al., 2001). Entretanto, as fibras previamente branqueadas contatadas com outros efluentes mais carregados, quando recuperadas no decantador primário, apresentam coloração escura e baixo valor comercial. Assim, a segregação de efluentes se mostra de suma importância para a eficiência técnica e econômica do tratamento de efluentes da indústria de celulose. A recuperação de fibras no efluente, logo após o estágio de branqueamento, permite o retorno destas fibras para o processo e a redução de carga orgânica do efluente.

O uso de decantação ou coagulação/floculação para remoção de fibras requer elevadas áreas, o que geralmente é um problema para indústrias de polpa celulósica. Uma alternativa é o emprego de processos de separação por membranas. Os processos de separação por membranas são processos que utilizam uma barreira seletiva (membrana) que sob a ação de uma força motriz podem promover a separação de determinados componentes de uma solução ou suspensão (SCHNEIDER \& TSUTIYA, 2001). A aplicação de processos de separação por membranas em indústria de polpa celulósica tem aumentado significativamente nos últimos anos devido à elevada qualidade do efluente produzido, possibilitando o fechamento do circuito de água dentro da indústria, ao baixo requerimento de área e ao fato de serem sistemas modulares e flexíveis a alteração de escala.

Apesar das vantagens, a incrustação de membranas tem sido, algumas vezes, um fator limitante para a aplicação destes processos. A incrustação das membranas resulta em uma contínua redução do fluxo até a um ponto em que o fluxo de permeado se torna independente do gradiente de pressão (FIELD et al., 1995; HOWELL, 1995). No caso do uso de processos de separação por membranas para o tratamento de efluentes de indústrias de celulose, a incrustação não pode ser totalmente evitada (WEIS et al., 2005), sendo necessária a adoção de estratégias para sua minimização.

A seleção adequada das características da alimentação, tais como pH e temperatura da alimentação, das condições hidrodinâmicas do sistema e das técnicas de limpeza, pode ser usada para minimizar a incrustação. Entretanto é necessário conhecer os mecanismos de incrustação envolvidos para selecionar os métodos de mitigação mais adequados. Dessa forma, o objetivo deste artigo foi avaliar o emprego de microfiltração (MF) na remoção de fibras de efluentes de branqueamento alcalino de polpa celulósica para diferentes condições operacionais.

\section{Metodologia}

\section{Efluente de branqueamento de polpa celulósica}

O efluente do branqueamento utilizado para a realização dos experimentos foi fornecido por uma empresa brasileira de celulose, cujo processo de produção é o processo Kraft. A empresa possui duas linhas de produção que utilizam digestores contínuos, deslignificação com oxigênio e sequências de branqueamento com estágios ácido a quente com dióxido de cloro e alcalino com peróxido de hidrogênio em série $\left(\mathrm{D}_{\mathrm{HT}}(\mathrm{EP}) \mathrm{D}_{1} \mathrm{P}\right)$ e com fechamento parcial do circuito de água. O estudo foi realizado empregando o efluente denominado alcalino coletado no segundo estágio do branqueamento (extração alcalina com peróxido de hidrogênio). O efluente era coletado semanalmente e conservado sob refrigeração. Na Tabela 1 é apresentada a caracterização físico-química do efluente empregado neste estudo.

\section{Sistema de microfiltração}

O sistema de MF é constituído de um reservatório de alimentação, bomba para circulação da alimentação, módulo com 
membranas de MF, manômetro, rotâmetro (alimentação e permeado) e dois reservatórios de $10 \mathrm{~L}$, um para coleta do permeado e outro para coleta do retido, adquirido da PAM Membranas Seletivas Ltda. Na Figura 1A e B são apresentados esquema ilustrativo e foto do sistema, respectivamente.

Os módulos de membranas de fibra oca empregados apresentam conformação semelhante a um trocador de calor tipo casco e tubo. A alimentação dos módulos foi realizada no interior da carcaça e o permeado foi coletado no interior das fibras ocas na extremidade do módulo oposta a da alimentação. A membrana empregada é de poli(imida) com tamanho médio de poros de 0,5 um e área de filtração de 0,05 $\mathrm{m}^{2}$. O sistema de MF permitia operação com capacidade de filtração média para o efluente de 2 L.h.' ${ }^{-1}$.

\section{Efeito das condições operacionais no fluxo permeado}

O efeito das condições operacionais no fluxo permeado foi avaliado através do monitoramento do perfil de fluxo durante a operação em diferentes condições de velocidade de escoamento, pH da alimentação, temperatura e pressão de operação. Os ensaios foram realizados com permeado e concentrado retornando para o tanque de alimentação objetivando manter as mesmas condições da alimentação.

\section{Efeito da variação do número de Reynolds}

Para a avaliação das condições hidrodinâmicas variou-se o número de Reynolds em 1.226, 1.653 e 2.043, correspondendo a vazões de alimentação de 72, 96 e 144 L.h ${ }^{-1}$, respectivamente, observando-se os perfis dos fluxos permeados em função do tempo usando o efluente bruto $(\mathrm{pH}=10,6)$ em temperatura ambiente. Após o término de cada teste, o módulo era submetido ao processo de limpeza física (recirculação de água e retrolavagem) e química (o módulo de membrana era mantido em um banho de ultrassom em solução de $\mathrm{NaOCl}$, com concentração de 500 mg.L $\mathrm{L}^{-1}$, por 20 minutos)

\section{Efeito do pH da alimentação}

Para avaliar o efeito do $\mathrm{pH}$ no fluxo permeado, observou-se o perfil do fluxo permeado em função do tempo usando o efluente em pH 7, 10 e 10,6 (pH do efluente bruto). O ajuste do pH foi realizado empregando ácido fosfórico concentrado e solução hidróxido de sódio (50\%). Os permeados das operações com efluente

Tabela 1 - Características físico-químicas do efluente.

\begin{tabular}{lcccccccccc} 
Parâmetros & Unidade & Média & Mínimo & Máximo & Parâmetros & Unidade & Média & Mínimo & Máximo \\
\hline DQO & mg. $\mathrm{L}^{-1}$ & 2.804 & 1.697 & 4.086 & Sólidos totais & $\mathrm{mg} \cdot \mathrm{L}^{-1}$ & 5.969 & 5.658 & 7.688 \\
DBO5 & $\mathrm{mg} \cdot \mathrm{L}^{-1}$ & 741 & 320 & 1.192 & Sólidos totais fixos & $\mathrm{mg} \cdot \mathrm{L}^{-1}$ & 3.755 & 3.820 & 5.018 \\
\hline Cor aparente & $\mathrm{uH}$ & 756 & 250 & 1.300 & Sólidos totais voláteis & $\mathrm{mg} \cdot \mathrm{L}^{-1}$ & 1.736 & 1.170 & 2.670 \\
\hline Cor real & $\mathrm{uH}$ & 357 & 320 & 450 & Sólidos suspensos totais & $\mathrm{mg} \cdot \mathrm{L}^{-1}$ & 1.027 & 223 & 1539 \\
$\mathrm{pH}$ & - & 11 & 10,3 & 11,2 & Sólidos suspensos fixos & $\mathrm{mg} \cdot \mathrm{L}^{-1}$ & 55 & 20 & 104 \\
\hline Alcalinidade & $\mathrm{mg} \cdot \mathrm{L}^{-1}$ & 1.760 & 915 & 4.831 & Sólidos suspensos voláteis & $\mathrm{mg} \cdot \mathrm{L}^{-1}$ & 972 & 192 & 1.518
\end{tabular}

DQO: demanda química de oxigênio; DBO5: demanda bioquímica de oxigênio.
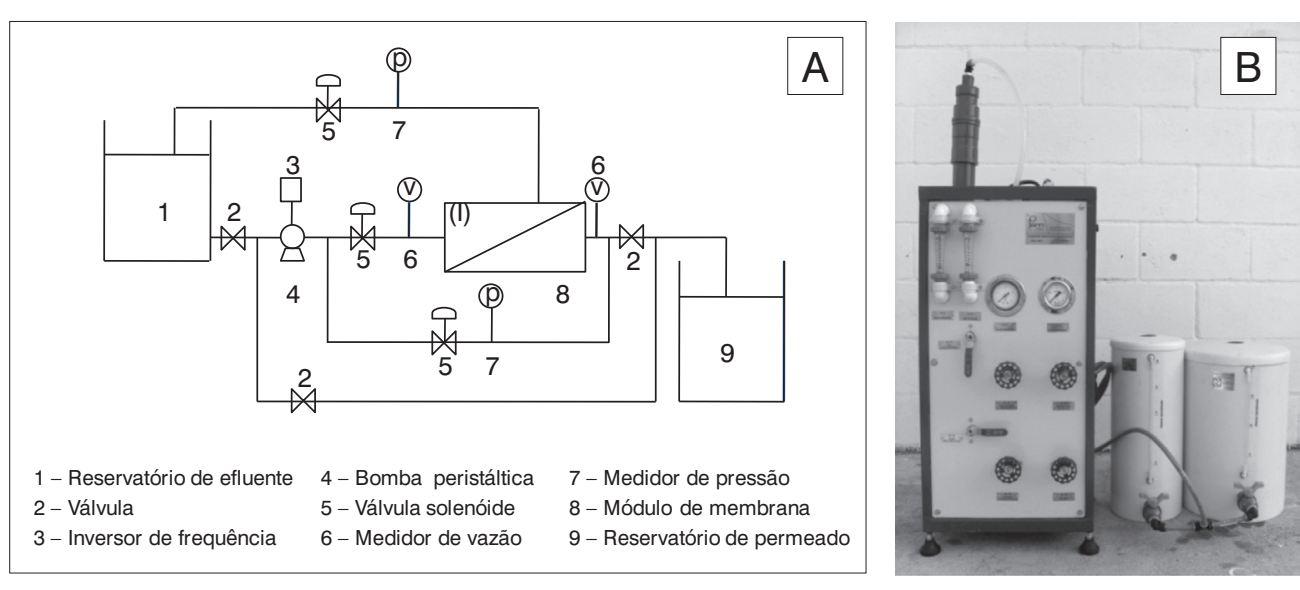

Figura 1 - (A) Esquema do sistema de microfiltração e (B) foto da unidade de microfiltração. 
em pH 7 e 10 também foram caracterizados quanto à concentração de DQO, sólidos suspensos totais (SS), Na, Ca, Mg, Mn e Fe por espectrofotometria de absorção atômica em conformidade com Standard Methods for the Examination of Water and Wastewater (APHA, 2005). Após o término de cada teste o módulo era submetido ao processo de limpeza física e química.

\section{Efeito da temperatura da alimentação}

O efluente de branqueamento apresenta temperaturas entre $60-80^{\circ} \mathrm{C}$. Para avaliar a viabilidade da aplicação do processo de MF sem uma etapa de resfriamento intensa do efluente foi avaliado o efeito da temperatura no fluxo de permeado. As temperaturas de alimentação avaliadas foram: 28,43 e $48^{\circ} \mathrm{C}$. Para cada temperatura foi avaliado o perfil do fluxo permeado em função da pressão de operação e a concentração de SS no permeado. Antes da operação com outro valor de temperatura, o módulo foi submetido ao processo de limpeza.

\section{Determinação da pressão de operação}

Dada as condições ótimas de velocidade de escoamento, temperatura e pH da alimentação, a pressão de operação foi avaliada através da determinação da pressão crítica nas condições preestabelecidas. Para obtenção da pressão crítica, foram realizados ensaios nos quais a pressão foi fixada e o fluxo de permeado foi monitorado por 15 minutos logo após o qual a pressão foi incrementada sucessivamente com respectivo acompanhamento do fluxo de permeado. Os valores de pressões avaliados foram de $0,5,0,75,1,0,1,25$ e 1,5 bar.

\section{Operação sob condições operacionais ótimas}

Após a determinação das condições operacionais ótimas, o sistema de MF operou sob tais condições para investigação do mecanismo de incrustação, da operação com concentração de fibras na alimentação, dos métodos de minimização de incrustação e das características do permeado e do concentrado para retorno a linha de produção.

\section{Concentração de fibras de celulose}

A concentração de fibras de celulose no efluente de branqueamento depende das condições operacionais do processo. Desta forma é desejável que o sistema de MF suporte operar com estas oscilações na concentração de fibras de celulose. Para avaliação do efeito da concentração de fibras de celulose no processo de MF, primeiramente, o efluente foi concentrado por meio de decantação e descarte de sobrenadante. As concentrações de fibras avaliadas foram de 240, 680, 1.096 e $1.685 \mathrm{mg} . \mathrm{L}^{-1}$.

\section{Investigação da incrustação}

A avaliação da incrustação foi realizada através da avaliação do perfil do fluxo de permeado do efluente $\left(J_{v}\right)$ em relação ao fluxo permeado de água pura para a membrana nova $\left(J_{i}\right)$. Também foram avaliadas a resistência total da incrustação e as resistências de cada parcela que constitui a resistência total (resistência da membrana $\left(R_{m}\right)$, adsorção estática $\left(R_{a}\right)$ bloqueio dos poros $\left(R_{p}\right)$ e torta $\left(R_{t}\right)$. Para o cálculo destas resistências, foi empregado o método de resistências em série proposto por Choo e Lee (1998) para o qual é necessária a determinação dos fluxos $J_{i}, J_{a}, J_{f}$ e $J_{v^{*}}$ O fluxo $J_{i}$ foi determinado para a permeação de água pura para a membrana nova, etapa esta realizada na caracterização da permeabilidade da membrana. O fluxo J foi determinado para a permeação de água pura após adsorção estática do efluente por três horas (sem pressurização). Já o fluxo $\mathrm{J}_{\mathrm{f}}$ foi determinado pela permeação de água pura na membrana incrustada e $\mathrm{J}_{\mathrm{v}}$, foi determinado pela permeação do efluente sob as condições preestabelecidas (pressão de 1 bar e vazão de 96 L.h.' ${ }^{-1}$ ) por 3 horas. Dados os valores dos fluxos $J_{f}, J_{v}, J_{i} e J_{a}$, os valores das resistências de $R_{a}$, $R_{p}$ e $R_{T}$ foram obtidos empregando-se as Equações 1 a 3 .

$R_{a}=\left(\frac{J_{i}}{J_{a}}-1\right) R_{m}$

$R_{p}=\left(\frac{J_{i}}{J_{f}}-1\right) R_{m}-R_{a}$

$R_{T}=\left(\frac{J_{i}}{J_{v}}-1\right) R_{m}-R_{a}-R_{p}$

\section{Resultados e discussões}

\section{Efeito das condições operacionais no fluxo permeado}

Efeito da variação do número de Reynolds

Para a avaliação do efeito da variação do número de Reynolds foram observados a permeabilidade da membrana e os perfis dos fluxos de permeado em função do tempo de operação usando o efluente bruto em temperatura ambiente e número de Reynolds de $1.226,1.653$ e 2.043 , os quais correspondem ao emprego de vazões de alimentação de 72, 96 e 144 L.h ${ }^{-1}$, respectivamente. Na Figura 2 são apresentadas as relações entre o fluxo permeado e a pressão de operação para cada condição avaliada, assim como a comparação com os valores obtidos com água microfiltrada. 
A permeabilidade da membrana alimentada com efluente é de 27, 32 e 36 L. $\mathrm{m}^{-2} \cdot \mathrm{h}^{-1} \cdot$ bar $^{-1}$ para Reynolds de 1.226, 1.653 e 2.043, respectivamente.

Observa-se uma grande diferença entre as permeabilidades obtidas na MF de água pura e na MF do efluente, o que se deve a incrustação da membrana. A pequena diferença da permeabilidade da membrana para diferentes condições de Reynolds provavelmente se deve ao grande potencial incrustante do efluente, promovendo o depósito intenso de fibras, o qual não é significativamente afetado pelo aumento da velocidade de escoamento (número de Reynolds). Na Figura 3 são apresentados os perfis de fluxo de permeado em relação ao tempo de permeação para os diferentes números de Reynolds avaliados.

Observa-se a rápida redução do fluxo com o tempo de permeação para as diferentes condições avaliadas, correspondendo a uma redução de $68 \%$ para Re de 1.226 e $66 \%$ para Re de 1.653 e 2.043 . Esta redução do fluxo pode ser associada ao depósito de fibras de celulose na superfície das fibras de membrana levando a formação de torta. Na Figura 4 são apresentados os valores da rejeição da membrana em diferentes condições de Reynolds em termos de DQO e sólidos suspensos. O resultado da análise de sólidos suspensos totais pode ser associado diretamente à presença de fibras, uma vez que a maior parte dos sólidos suspensos presentes no efluente é constituída de sólidos suspensos voláteis correspondentes a fibras de celulose conforme análise prévia realizada pelos autores.

Observa-se que o emprego de MF é eficiente para a remoção de fibras de celulose, com rejeição média de 99\% produzindo permeado com concentração média de sólidos suspensos totais de $10 \mathrm{mg} \cdot \mathrm{L}^{-1}$. Observa-se também que não houve diferenças significativas entre os valores de rejeição em diferentes condições de Reynolds. Isto provavelmente se deve ao fato de que o tamanho dos poros é menor do que o tamanho das fibras de celulose. Em relação à rejeição em termos de DQO, observam-se baixos valores de rejeição, o que já era esperado, pois membranas de MF não são adequadas para remoção de materiais solúveis. A rejeição de DQO encontrada provavelmente se deve as fibras de celulose removidas.

\section{pH da alimentação}

$\mathrm{Na}$ Figura 5 são apresentados os perfis de fluxo permeado para alimentação com efluente em pH 7, 10 e 10,6. Ao contrário do esperado, observa-se que o aumento do $\mathrm{pH}$ intensificou a redução do fluxo. De acordo com a literatura, os problemas de incrustação na MF de efluente de branqueamento aumentam quando o pH é menor que 10,3, porque este valor de pH está associado ao valor de pKa dos grupos ácidos fenólicos que são encontrados na lignina (NORDIN \& JÖNSSON, 2006). O resultado encontrado, provavelmente, se deve a baixa concentração de compostos fenólicos, prevalecendo outros fatores.

$\mathrm{Na}$ Tabela 2 são apresentados os resultados da caracterização dos permeados das operações com alimentação em pH 7 e 10 .

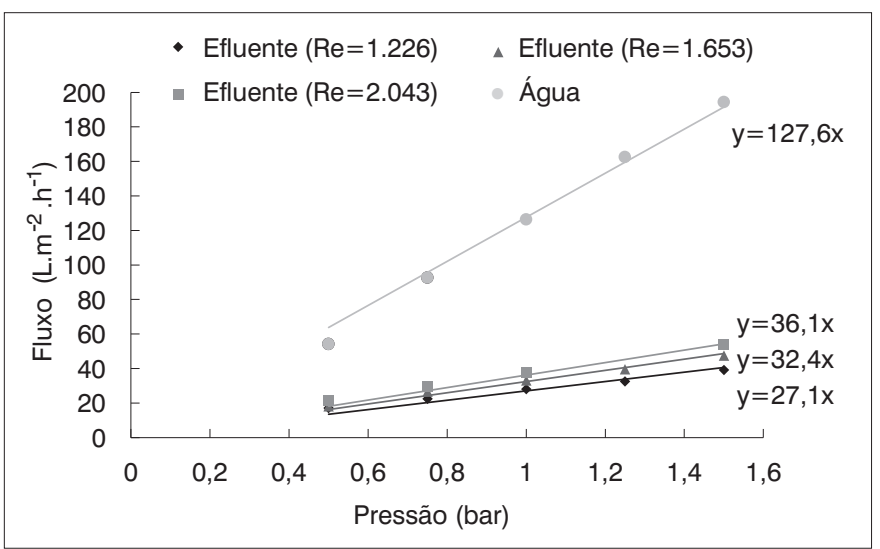

Figura 2 - Permeabilidade hidráulica do módulo alimentado com água e com efluente sob diferentes condições de número de Reynolds.

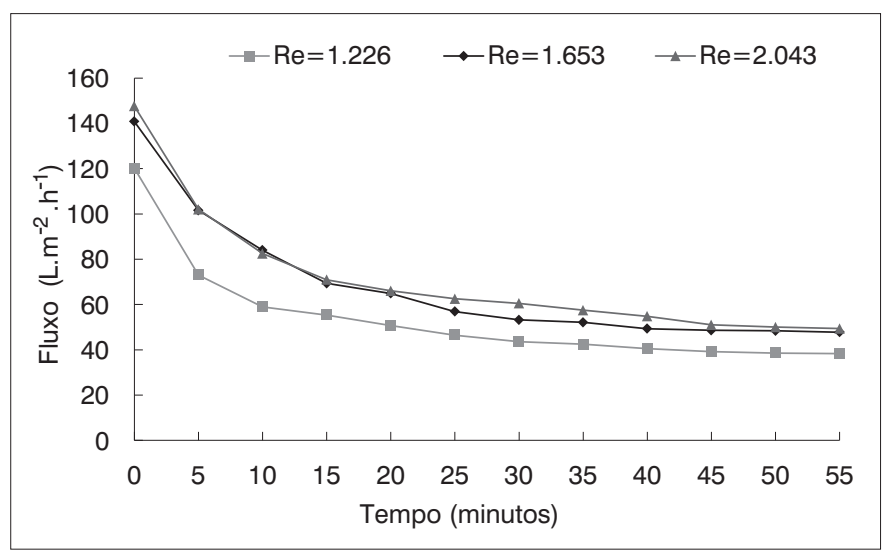

Figura 3 - Perfil do fluxo de permeado com o tempo de operação em diferentes condições de Reynolds $\left(p=1,0\right.$ bar, temperatura $\left.=28^{\circ} \mathrm{C}, \mathrm{pH} 10,6\right)$.

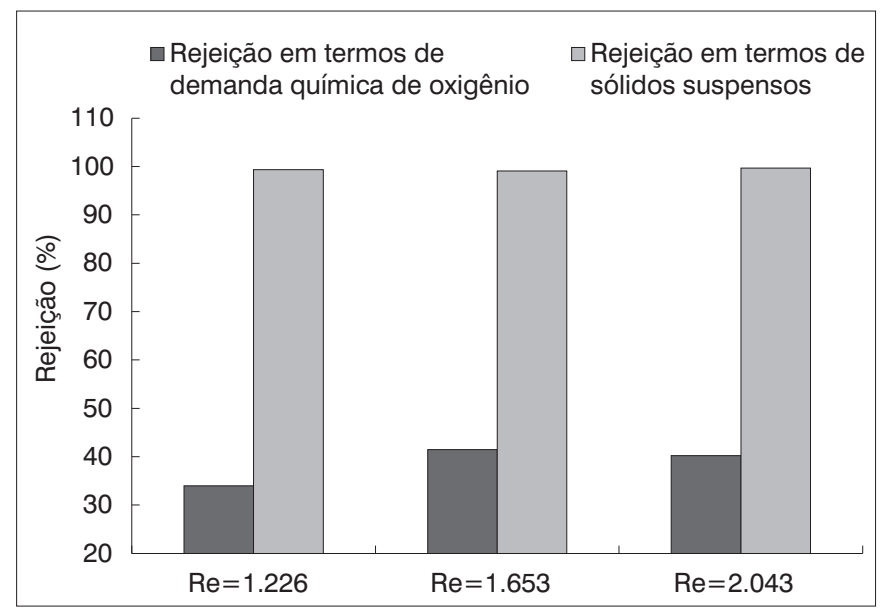

Figura 4 - Rejeição de demanda química de oxigênio e sólidos suspensos em diferentes condições de Reynolds ( $p=1,0$ bar, pH 10,6, temperatura $=25^{\circ} \mathrm{C}$ ) 
Observa-se que não há diferenças significativas entre a concentração de componentes inorgânicos nos permeados das operações com alimentação com pH 7 e 10. Em relação à concentração de DQO, observa-se uma maior concentração de DQO no permeado da operação com alimentação em $\mathrm{pH}$ 10, o que pode ser relacionado a fragmentos de lignina que de acordo com a literatura são solubilizados em pH alcalino (GIERER, 1982). Esta hipótese é reforçada pela redução da cor após redução do pH. Em solução os fragmentos de lignina assumem uma forma compacta e esférica (ADAMS \& EDE, 1997) e natureza hidrofóbica, características estas que podem ser associadas à maior incrustação da membrana operada com alimentação em pH 10 devido à maior adsorção dos mesmos na superfície da membrana.

Os maiores fluxos de permeado obtidos em pH 7 evidenciam que a opção mais viável é o ajuste do $\mathrm{pH}$ antes da unidade de MF, pois ocasiona maior produção de permeado. Além disso, nos casos em que a MF é empregada como pré-tratamento de processos biológicos, seria necessário de qualquer maneira o ajuste do pH da alimentação para valores em torno de sete antes da etapa

Tabela 2 - Características dos permeados das operações com alimentação em pH 7 e 10.

\begin{tabular}{lccc} 
Parâmetros & Unidade & $\mathrm{pH} 7$ & $\mathrm{pH} 10$ \\
\hline DQO solúvel & $\mathrm{mg} \cdot \mathrm{L}^{-1}$ & 1.401 & 1.844 \\
$\mathrm{Na}$ & $\mathrm{mg} \cdot \mathrm{L}^{-1}$ & 5240 & 5370 \\
$\mathrm{Fe}$ & $\mathrm{mg} \cdot \mathrm{L}^{-1}$ & 0,11 & 0,17 \\
$\mathrm{Ca}$ & $\mathrm{mg} \cdot \mathrm{L}^{-1}$ & 4,6 & 4,6 \\
$\mathrm{~K}$ & $\mathrm{mg} \cdot \mathrm{L}^{-1}$ & 197 & 199 \\
$\mathrm{Mn}$ & $\mathrm{mg} \cdot \mathrm{L}^{-1}$ & 0,24 & 0,22 \\
$\mathrm{Mg}$ & $\mathrm{mg} \cdot \mathrm{L}^{-1}$ & 1,1 & 1,1 \\
Cor & $\mathrm{uH}$ & 67 & 105 \\
\hline Potencial Zeta & $\mathrm{mV}$ & -48 & -28 \\
\hline
\end{tabular}

DQO: demanda química de oxigênio.

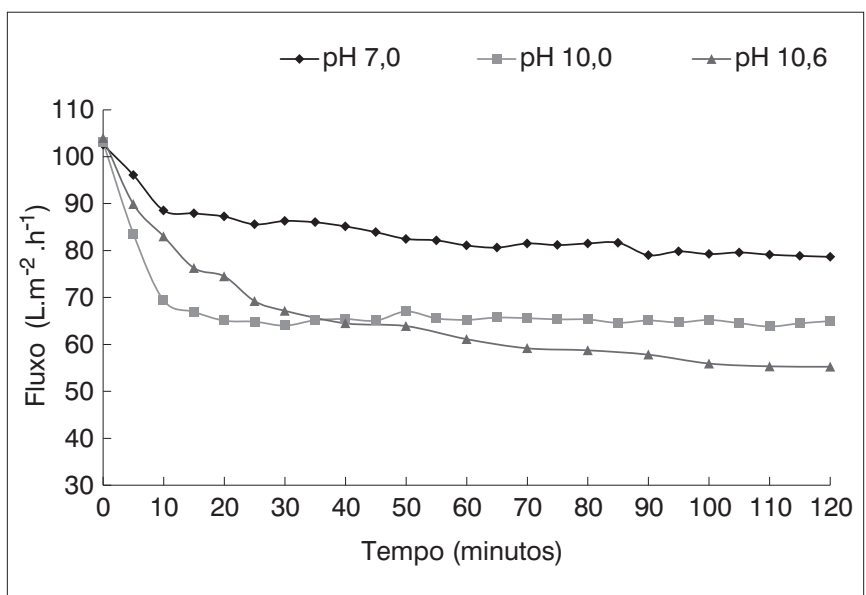

Figura $\mathbf{5}$ - Efeito do pH no fluxo permeado em relação ao tempo de permeação $\left(p=1,0\right.$ bar, vazão de alimentação $=96 \quad$ L.h $h^{-1}$, temperatura $=25^{\circ} \mathrm{C}$ ). biológica, uma vez que esse é o pH ótimo para o crescimento e manutenção dos microrganismos.

\section{Temperatura}

Uma vez que o efluente de branqueamento possui elevadas temperaturas $\left(60-80^{\circ} \mathrm{C}\right)$, foi avaliada a viabilidade da aplicação do processo de MF apenas com uma etapa de resfriamento intermediária, sem a necessidade de se resfriar o efluente à temperatura ambiente. Na Figura 6 é apresentado o perfil do fluxo permeado em função do tempo para cada condição de temperatura.

Observa-se que não há diferenças significativas entre os perfis de fluxo permeado em diferentes temperaturas, embora se espere que o aumento da temperatura resulte na redução da viscosidade e, consequentemente, aumento do fluxo de permeado. Este resultado mostra que a redução na viscosidade apresenta menor influência no fluxo do que a resistência proporcionada pela formação da torta. Entretanto, os resultados mostram que não há comprometimento na operação em temperaturas elevadas uma vez que não houve alteração da permeabilidade e do grau de rejeição da membrana. Vale ressaltar que a operação em temperaturas mais próximas da temperatura do efluente é inviável devido a restrições operacionais da membrana, cuja temperatura máxima de operação é de $50^{\circ} \mathrm{C}$.

\section{Pressão de operação}

Dada as condições ótimas de velocidade de escoamento, temperatura e pH da alimentação, a pressão de operação foi avaliada através da avaliação da pressão crítica, pressão a partir da qual observa-se a incrustação da membrana. A pressão crítica foi determinada tanto para o efluente com $\mathrm{pH}$ próximo do bruto (pH 10) quanto para o efluente com pH ajustado em 7. A pressão

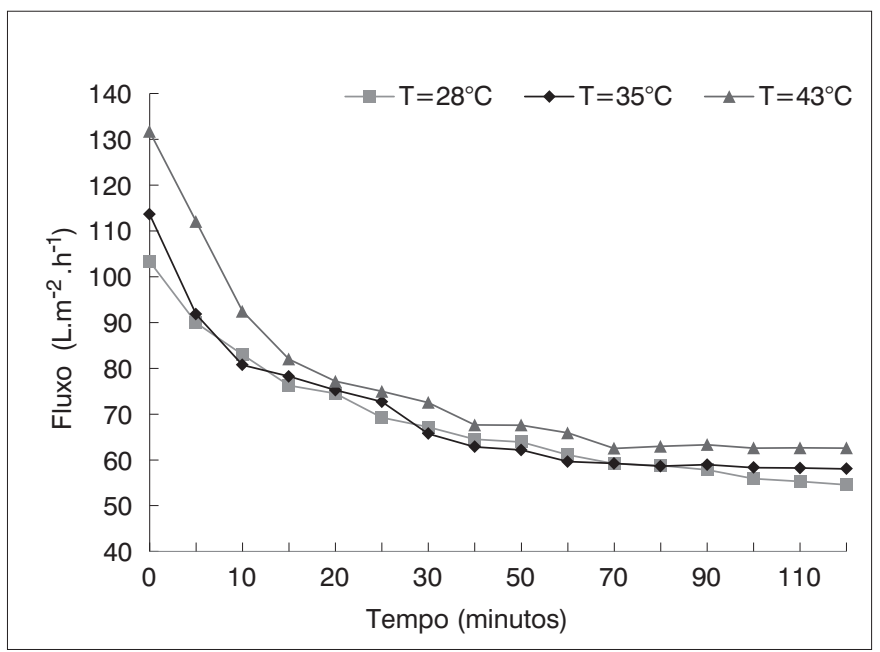

Figura 6 - Efeito da temperatura no fluxo permeado em relação ao tempo de permeação $\left(p=1,0\right.$ bar, vazão de alimentação $=96$ L.h $\left.^{-1}, \mathrm{pH} 7\right)$. 
crítica é definida como aquela em que a relação entre pressão e fluxo de permeado se torna não linear. A Figura 7 apresenta a relação entre fluxo de permeado e pressão de operação usada para determinação de pressão crítica.

Observa-se que a pressão crítica equivale a 1,0 e 0,75 bar para operação com efluente em pH 7 e 10, respectivamente, correspondendo a um fluxo de $82 \mathrm{~L} \cdot \mathrm{m}^{-2} \cdot \mathrm{h}^{-1}$ para efluente com $\mathrm{pH} 7 \mathrm{e}$ $38 \mathrm{~L} \cdot \mathrm{m}^{-2} \cdot \mathrm{h}^{-1}$ para efluente com $\mathrm{pH} 10$. O aumento da pressão crítica com a redução do $\mathrm{pH}$ da alimentação provavelmente se deve a menor resistência da incrustação na operação com pH 7 em relação a formada em pH 10 conforme discutido anteriormente.

Sendo assim, esta etapa de avaliação das condições operacionais evidenciou melhor desempenho da operação de MF empregando $\mathrm{pH} 7$, pressão de 1 bar e Re de 1.653. Em relação à temperatura, não foi determinado um valor ótimo, uma vez que não houve diferenças significativas entre as operações em diferentes temperaturas.

\section{Operação sob condições operacionais ótimas}

Efeito da variação da concentração de fibras

Na Figura 8 são apresentados os perfis do fluxo permeado em função do tempo para cada condição de concentração de alimentação.

Observa-se a redução do fluxo com o aumento da concentração de alimentação, o que se deve provavelmente ao maior depósito de fibras de celulose na superfície da membrana, formando uma torta mais espessa. Na Figura 9 é apresentada a relação entre o fluxo de permeado após sua estabilização e o teor de sólidos suspensos totais na alimentação e no permeado. Embora se note um decaimento do fluxo de permeado à medida em que

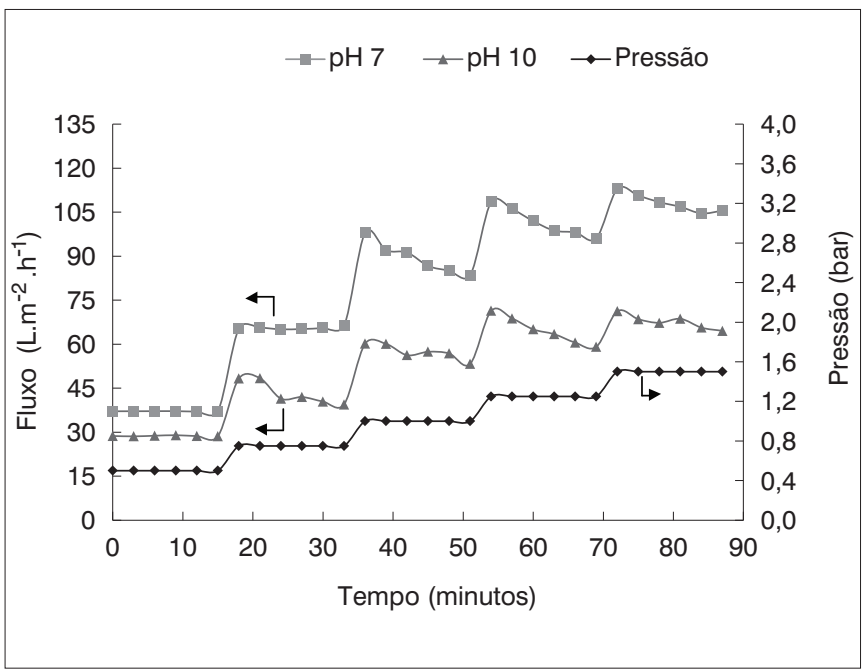

Figura 7 - Relação entre fluxo de permeado e pressão de operação para determinação de pressão crítica. a concentração de sólidos na alimentação aumenta de 240 para $680 \mathrm{mg} . \mathrm{L}^{-1}$, observa-se que não há diferença relevante nesse parâmetro ao se elevar a concentração de sólidos de 680 para $1.685 \mathrm{mg} . \mathrm{L}^{-1}$, mostrando que o sistema pode suportar variações de concentração de sólidos (fibras), variação esta frequente no efluente em questão.

Verifica-se também que a concentração de sólidos suspensos (SS) no permeado apresentou um pequeno aumento com o aumento da concentração de sólidos na alimentação. Entretanto este aumento pode ser considerado pouco relevante em relação à concentração de sólidos na alimentação. Ao comparar a eficiência do processo $(95,98,98,99 \%$ para concentração da alimentação de $240,680,1.096$ e $1.685 \mathrm{mg} . \mathrm{L}^{-1}$, respectivamente) a não expressividade desta diferença se torna mais aparente. A elevada eficiência de remoção de fibras pode ser associada ao fato de que

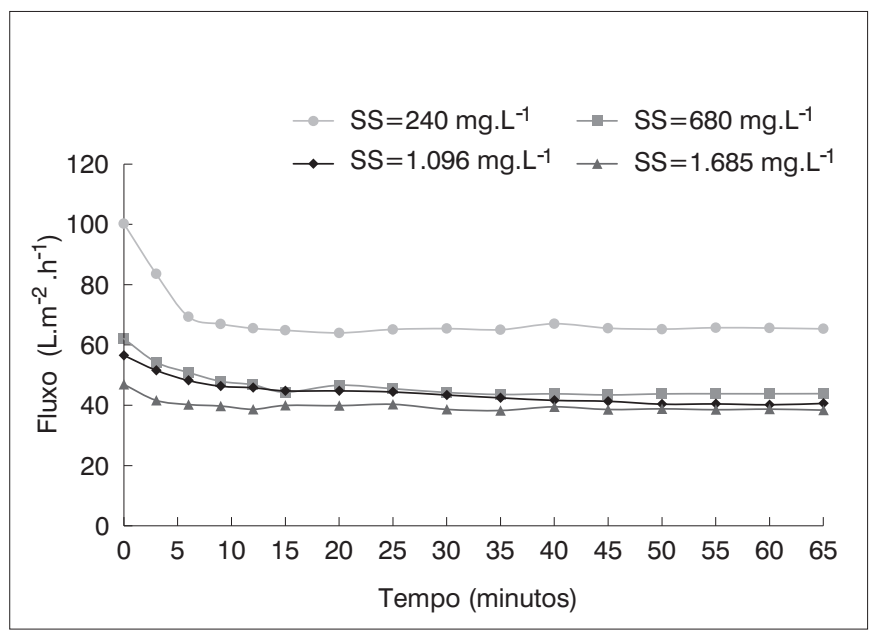

Figura 8 - Efeito da concentração de fibras na alimentação no fluxo permeado em relação ao tempo de permeação $(p=1$ bar, vazão de alimentação $=96$ L. $h^{-1}$, pH 7, temperatura $=25^{\circ} \mathrm{C}$ ). SS: sólidos suspensos

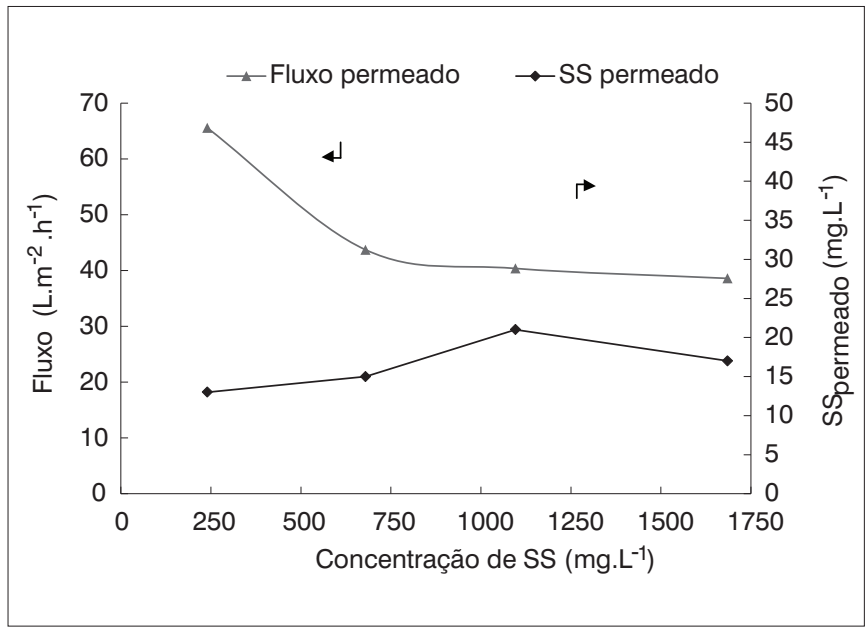

Figura 9 - Relação entre fluxo de permeado e concentração de sólidos suspensos no permeado e concentração de sólidos suspensos na alimentação. SS: sólidos suspensos. 
o tamanho médio das fibras é superior ao tamanho dos poros resultando em uma elevada rejeição pela membrana.

Vale ressaltar que a MF do efluente de branqueamento além de apresentar elevada remoção/recuperação das fibras de celulose em relação aos tratamentos físicos e/ou químicos convencionais empregados no tratamento primário deste efluente como sedimentação, coagulação/floculação e flotação, os quais geralmente apresentam eficiência de remoção em torno de 80\% (THOMPSON et al., 2001), possibilita ainda que o concentrado possa ser retornado ao processo já que não é adicionado produto químico auxiliar, como na coagulação/floculação e flotação e a polpa obtida apresenta elevada concentração de fibras.

\section{Investigação da incrustação}

O sistema de MF foi operado nas condições ótimas objetivando avaliar o mecanismo de incrustação. A avaliação da incrustação foi realizada através da avaliação da resistência total da incrustação e das resistências da membrana $\left(R_{m}\right)$, adsorção estática $\left(R_{a}\right)$, bloqueio dos poros $\left(R_{b p}\right)$ e torta $\left(R_{t}\right)$. As resistências foram avaliadas mantendo a alimentação em pH 7 e em pH 10. $\mathrm{Na}$ Figura 10 são apresentados os valores das resistências $R_{m}, R_{a}$, $\mathrm{R}_{\mathrm{bp}}$ e $\mathrm{R}_{\mathrm{t}}$ para alimentação com pH 7 e 10 .

Observa-se que, conforme previsto, a incrustação da membrana se deve principalmente à formação de torta, tanto em pH 7 quanto em pH 10. A resistência devido `a formação de torta correspondeu a 39 e 37\% da resistência total para alimentação com pH 7 e 10, respectivamente. Entretanto, observa-se que também há presença de incrustação devido à adsorção estática e bloqueio dos poros. A redução do pH da alimentação de 10 para 7 resultou na redução de $83 \%$ da resistência devido à adsorção estática e $13 \%$ da resistência devido à formação da torta, e no aumento de $16 \%$ da resistência devido ao bloqueio dos poros. O aumento do bloqueio de poros pode ser associado à redução da formação de torta e da adsorção que deixou a superfície da membrana mais disponível ao bloqueio de poros.

O melhor desempenho do sistema de MF com alimentação com pH 7 provavelmente está relacionado à redução da adsorção, uma vez que a redução desta foi a principal contribuinte para a redução da resistência total. Correlacionando estes resultados com os resultados da composição do permeado apresentado na Tabela 1, observa-se que, ao reduzir o pH da alimentação de 10 para 7 , a concentração de DQO reduziu e, conforme discutido anteriormente, esta redução pode ser associada à insolubilidade de fragmentos de lignina que de acordo com a literatura são solúveis em $\mathrm{pH}$ alcalino e insolúveis em meio ácido. Estes compostos geralmente apresentam elevada massa molar e natureza hidrofóbica (FARDIM, 2002), podendo ser adsorvidas na superfície da membrana. Com a insolubilização destas substâncias, a adsorção diminui resultando em uma menor incrustação.

Os resultados da etapa de investigação do mecanismo de incrustação evidenciaram que para manutenção do fluxo é necessário o emprego de técnicas que possibilitem a remoção da torta. Desta forma, foi avaliado o emprego de recirculação no mesmo sentido da alimentação, recirculação no sentido contrário ao da alimentação e relaxamento como estratégias de limpeza física. Na Figura 11 são apresentados os perfis do fluxo de permeado com o tempo, obtidos com as diferentes formas de operação.

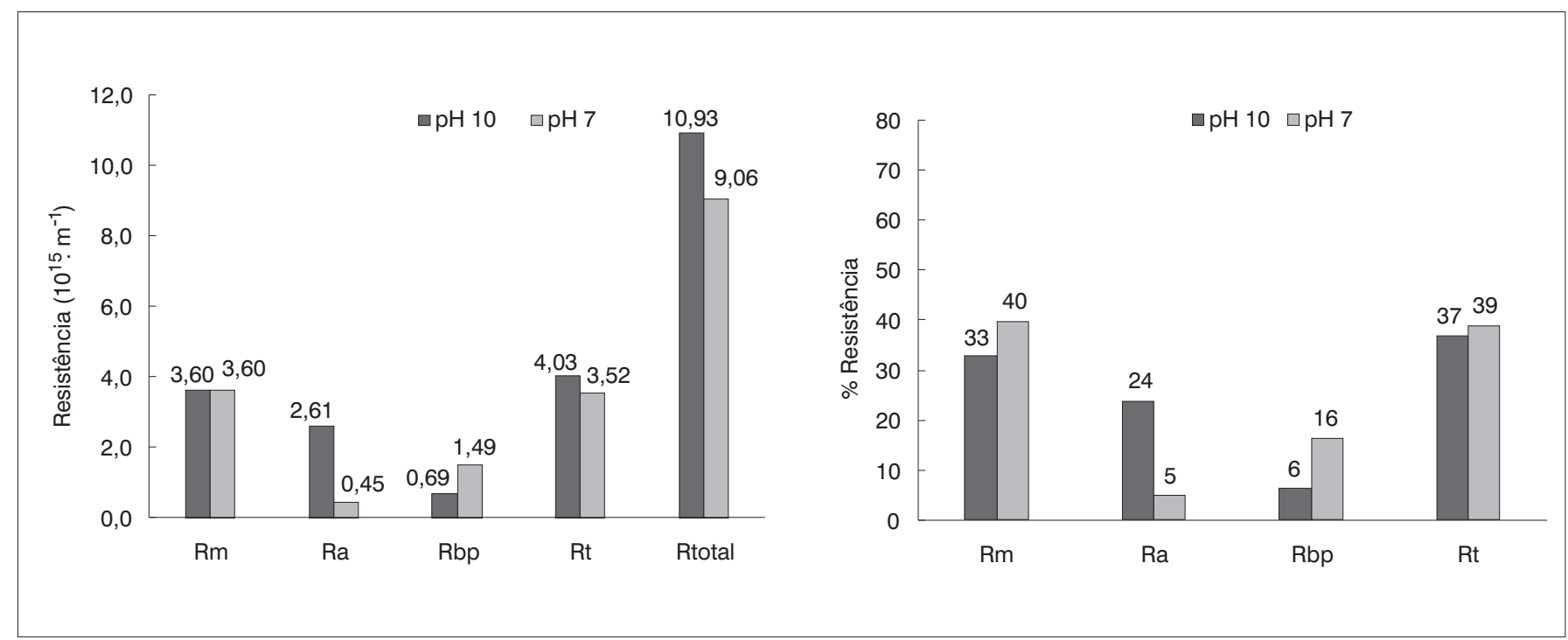

Figura 10 - Avaliação das resistências à permeação. (A) Valores das resistências $R_{m}, R_{a}, R_{b p}$ e $R_{t}$; (B) Contribuição em \% das $R_{m}$, $R_{a}, R_{b p}$ e $R_{t}$, para operação com alimentação em pH 7 e 10 . ( $p=1,0$ bar, vazão de alimentação $=96 \mathrm{~L} \cdot \mathrm{h}^{-1}$, temperatura $\left.25^{\circ} \mathrm{C}\right)$. 
Observa-se que todas as técnicas avaliadas permitem a recuperação do fluxo de permeado, sendo a recirculação no mesmo sentido da alimentação um pouco mais eficiente na recuperação do fluxo de permeado.

O uso de retrolavagem foi avaliado, mas não apresentou recuperação de fluxo permeado significativa. Uma possível justificativa para tal é que durante a retrolavagem os poros possivelmente são desbloqueados e principalmente a torta removida, entretanto o fluxo de permeado na retrolavagem não consegue arrastar as fibras do interior do módulo e, consequentemente, com o acionamento da permeação a torta se restabelece rapidamente. A retrolavagem poderia ser conjugada com a recirculação para melhorar a recuperação, entretanto, uma vez que a recirculação apresentou elevada recuperação do fluxo (média de 92\%), a retrolavagem pode ser evitada para evitar perda de produção, já que para a realização da retrolavagem o parte do permeado produzido é consumido.

\section{Conclusão}

Tendo em vista os resultados apresentados, o emprego de MF como pré-tratamento do efluente de branqueamento mostrou-se como uma alternativa viável para pré-tratamento, com rejeição de fibras média de 99\%, produzindo permeado adequado para posterior tratamento para remoção de matéria orgânica solúvel. Observou-se que o pH foi o fator que apresentou maior influência no fluxo permeado. A MF do efluente com $\mathrm{pH} 7$ apresentou maior desempenho em relação à remoção de fibras e menor incrustação. O melhor desempenho da operação de MF foi obtido

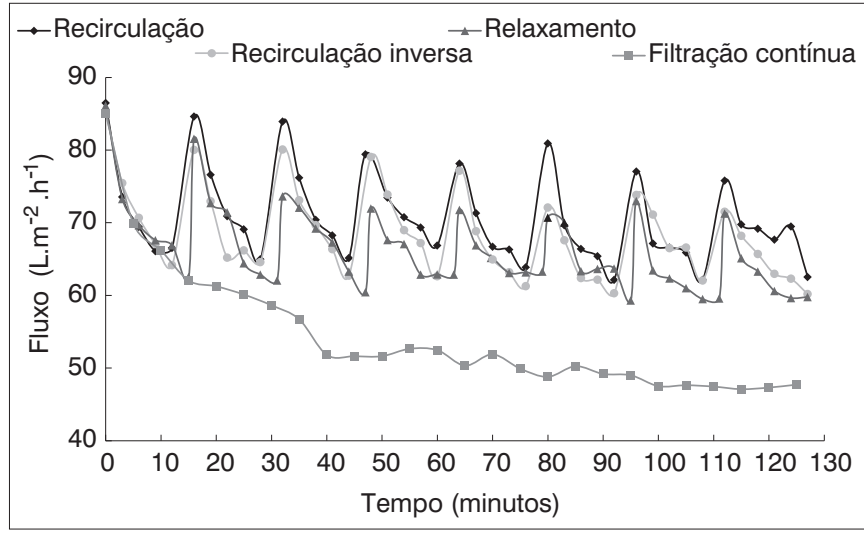

Figura 11 - Perfil do fluxo de permeado em diferentes modos de operação ( $p=1,0$ bar, vazão de alimentação $=96$ L.h $h^{-1}$, pH 7).

empregando pH 7, pressão de 1 bar e Reynolds de 1.653. Não houve diferenças relevantes entre as operações em diferentes temperaturas sugerindo que a redução na viscosidade apresenta menor influência no fluxo do que a resistência proporcionada pela formação da torta. Os resultados também sugerem que a redução do fluxo se deve à formação de torta, o que foi confirmado pelo teste de investigação de incrustação, através da avaliação das resistências à filtração, como o principal contribuinte na incrustação da membrana. Dessa forma, para manutenção do desempenho da MF é necessário o emprego de técnicas que possibilitem a remoção da torta. Dentre as técnicas avaliadas para a remoção da torta, o uso de recirculação apresentou-se viável por demandar menor perda de produção, uma vez que não há consumo do permeado produzido como na retrolavagem.

\section{Referências}

ADAMS, T.A. \& EDE, R.M. (1997) Isolation and characterization of lignin from Pinus radiata HTMP fibre. In: 9th International Symposium on wood and pulping chemistry, 1997, Tappi. Proceeding, ISWPC, v. 2.

AMERICAN PUBLIC HEALTH ASSOCIATION (APHA). (2005) Standard Methods for the Examination of Water and Wastewater. 20 ed. Washington, American Public Health Association.

BRYANT, C.W.; AVENELL, J.J.; BARKLEY, W.A.; THUT, R.N. (1992) The removal of chlorinated organics from conventional pulp and paper wastewater treatment systems. Water Science Technology, v. 26, n.1-2, p. 417-423.

CHOO, K.H. \& LEE, C.H. (1998) Hydrodynamic behavior of anaerobic biosolids during crossflow filtration in the membrane anaerobic bioreactor. Water Research, v. 32, p. 3387-3397.

FARDIM, P. (2002) O papel e química de superfície - Parte I - A superfície da fibra e a química da parte úmida. O papel, n. 4, p. 97-107.
FIELD, R.W; WU, D; HOWELL, J.A.; GUPTA, B.B. (1995) Critical flux concept for microfiltration fouling. Journal of Membrane Science, v. 100, p. 259-272.

GIERER, J. (1982) The chemistry of delignification. Part 1. General concept and reactions during pulping. Holzforschung, Berlin, v. 36, n. 1, p. $43-51$.

GRAVES, J.W. \& JOYCE, T.W. (1994) A critical review of the ability of biological treatment systems to remove chlorinated organics discharged by the paper industry. Water SA, v. 20, n. 2, p.155-160.

HOWELL, J. (1995) A. Sub-critical flux operation of microfiltration, Journal of Membrane Science, v. 107, p. 165-171.

IPPC. (2001) Integrated pollution prevention and control. Reference document on best available techniques in the pulp and paper industry, Chap 6. European Commission. December 2001. 
NORDIN, A.K. \& JÖNSSON, A.S. (2006) Case study of an ultrafiltration plant treating bleach plant effluent from a pulp and paper mill. Desalination, v. 201, p. 277-289.

SCHNEIDER, R.P. \& TSUTIYA, M.T. (2006) Membranas filtrantes para o tratamento de água, esgoto e água de reuso. São Paulo, Associação Brasileira de Engenharia Sanitária e Ambiental.

SOARES, C.H.L. \& DURÁN, N. (2001) Biodegradation of chlorolignin and lignin-like compounds contained into E1-pulp bleaching effluent by fungal treatment. Applied Biochemistry and Biotechnology, v. 82, n. 3, p. 956-968.

THOMPSON, G.; SWAIN, J.; KAY, M.; FORSTER, C.F. (2001) The treatment of pulp and paper mill effluent: a review. Bioresource Technology, v. 77, p. 275-286.

WEIS, A.; BIRD, M.R.; NYSTRÖM, M.; WRIGHT, C. (2005) The influence of morphology, hydrophobicity and charge upon the long-term performance of ultrafiltration membranes fouled with spent sulphite liquor. Desalination, v. 175, p. 73-85. 